\title{
TEORIA DAS RESTRIÇÕES E MAPEAMENTO DE PROCESSOS EM UM CENTRO DE DISTRIBUIÇÃO ${ }^{1}$
}

Evanielle Barbosa Ferreira - UNIFSA, Rhubens Ewald Moura Ribeiro - UNIFSA ${ }^{2}$

\section{RESUMO}

A logística é tida como uma ferramenta que objetiva proporcionar a disponibilidade de produtos para as organizações de forma eficiente e eficaz. Portanto, é preciso revisar os processos de forma que se adequem ao atendimento da demanda. $O$ estudo atual objetiva analisar o atraso gerado no fluxo das atividades logísticas de recebimento de materiais em um Centro de Distribuição - CD. Para o atingimento do objetivo, fez-se necessário descrever o processo de recebimento, identificar e analisar o gargalo do fluxo e sugerir melhorias que o minimize. $O$ trabalho classifica-se como uma pesquisa exploratória e descritiva que se baseia em dados e experiências coletadas por meio de um estudo de caso. Por meio de pesquisa documental e observação direta foram coletados dados que, após análises, permitiram constatar que a quantidade de pessoas para o processo de recebimento de mercadorias é o gargalo do sistema, além disso, durante o período em estudo, foi constatado que somente $36 \%$ da capacidade do CD estava em uso. $O$ remanejamento de pessoas para o momento de recebimento de mercadorias pode gerar em um aumento no número diário de caminhões para descarga. A pesquisa permitiu a aplicação da Teoria das Restrições em uma das etapas logísticas de um CD, permitindo um melhor entendimento do processo e identificação de pontos ineficientes.

Palavras-Chave: Centro de Distribuição. Fluxo de Recebimento. Gargalo. Logística. Teoria das Restrições.

\section{INTRODUÇÃO}

Em face das alterações do mercado cada vez mais globalizado, as empresas devem buscar melhorias contínuas para sobrevivência. A elevação das exigências nas demandas é um ponto desafiador que se busca alinha-la a capacidade ao longo da cadeia de suprimentos (MELO; ALCÂNTARA, 2011).

Se tratando de Centros de Distribuição, tem-se a movimentação e o gerenciamento do fluxo de produtos como um dos permanentes desafios logísticos. À medida que aumenta fluxo de processos, cresce a necessidade de controle e melhoria do mesmo, visando uma tratativa dos gargalos ao longo dos processos.

Diante do exposto, várias são as abordagens para tratamento desses gargalos. O estudo atual propõe-se a estudar a aplicação da Teoria das Restrições (TOC) em um Centro de Distribuição

1 Trabalho apresentado no Congresso Brasileiro Ciência e Sociedade (CBCS 2019), promovido pelo Centro Universitário Santo Agostinho, de 03 a 05 de outubro de 2019, em Teresina-PI.

2 Evanielle Barbosa Ferreira, Graduanda em Engenharia de Produção - UNIFSA; Rhubens Ewald Moura Ribeiro, Mestre em Administração - UFPR, Docente UNIFSA.

ISBN: 978-65-80968-11-4 DOI: $10.17648 /$ cbcs-2019-110672 


\section{gonVersSOCIENCIA \\ Inovação, Diversidlatle e Sustentahilitiade}

de uma empresa varejista que possui os seguimentos de Móveis e Eletrodomésticos e, por meio desta, fornecer auxílio para tomada de decisões.

O objetivo dessa pesquisa foi analisar o fluxo das atividades logísticas de recebimento de materiais da empresa, assim como, estudar o tempo de execução das mesmas para proposição de melhorias no processo. Para o atingimento do objetivo geral, fez-se necessário identificar e analisar o fluxo do processo de recebimento de produtos; Identificar o gargalo no fluxo logístico; Propor sugestões para melhoria de tais fatores que desencadeiam em gargalo.

\section{METODOLOGIA}

O estudo foi realizado em um Centro de Distribuição - CD de uma empresa varejista, da cidade de Teresina-PI. Partindo de uma problemática, fez-se possível identificar ineficiências no fluxo do recebimento de mercadorias correspondentes a atrasos na descarga dos produtos. Para o desenvolvimento da pesquisa considerou-se somente as atividades da etapa de recebimento. Os dados utilizados foram dos meses de Fevereiro e Março de 2019.

A pesquisa caracteriza-se como um estudo de caso por buscar examinar um fenômeno atual dentro do seu contexto, explanando uma experiência de forma organizada e crítica (ROESCH, 2013). Para isso, tem-se como ponto de partida uma revisão bibliográfica, que fundamenta o estudo e contribui à medida que permite aprofundamentos nos conceitos e relaciona a prática com a teoria.

Para que fosse ampliada a visão sobre os processos, adotou-se como técnica de coleta de dados a observação direta e a pesquisa documental que permitiram um aprofundamento e análises documentais, além da observação dos processos in loco. Para isso, foi realizado um acompanhamento do fluxo de recebimento, desde a entrada do caminhão até a liberação do mesmo. Esta análise proporcionou descrever o fluxo do processo e entender a realidade em estudo. Diante do exposto, pode-se classificar a pesquisa como exploratória, pois possui como finalidade esclarecer, desenvolver ou modificar ideias proporcionando uma ampla visão sobre o fato, bem como se trata de pesquisa descritiva ao objetivar caracterizar o funcionamento e detalhes do objeto de estudo (GIL, 2009).

\section{MAPEAMENTO DO FLUXO DE RECEBIMENTO}




\section{CONQEESSOC CIENCIA:SOCIEDADE \\ -}

O mapeamento de processos permite a identificação das etapas do fluxo de trabalho de forma visual. Além disso, tornam possível visualizar com mais clareza o fluxo de informação, materiais e tudo que envolve as tarefas do processo. O mapa dos processos ilustram as várias partes interessadas que impactam ou atuam no processo (BARBROW; HARTLINE, 2015).

O mapeamento diz respeito à descrição dos processos e como se relacionam as atividades umas com as outras dentro do processo, além de ser uma ferramenta gerencial analítica que objetiva a melhoria dos processos já existentes ou a implantação de novas estruturas voltada para processos (MARETH; BORBA, 2009; SLACK; CHAMBERS; JOHNSTON, 2018).

O mapeamento de processos permite que a empresa entenda o fluxo e modificações necessárias para agregação de valor ao mesmo. Milan e Versetti (2012), ressaltam que o mapeamento traz ganhos como um maior conhecimento dos processos, sendo possível monitorálos através dos indicadores que contribuem para melhorias na organização.

\section{TEORIA DAS RESTRIÇÕES (Theory of Constraints - TOC)}

A TOC baseia-se na ideia de interdependência dos processos, onde todos colaboram para o desempenho global. A restrição é qualquer coisa que impede o melhor desempenho do sistema, considerada o elo mais fraco da corrente. Sendo assim, a teoria tem por objetivo gerar uma otimização contínua do desempenho que qualquer organização tenha como meta, por meio do gerenciamento dos fatores (restrições) que a limitam. Mas, para isso, é necessário que seja encontrada a restrição do processo para que se alcance a meta. Além disso, existem dois tipos de restrições: as físicas e as não-físicas (GOLDRATT, 2014).

As restrições físicas relacionam-se aos recursos envolvidos no processo, tais como: máquinas e equipamentos, pessoal, instalação, veículos, etc. Sendo, nesse caso, o gargalo uma restrição por capacidade insuficiente. Recomenda-se que as restrições do tipo físicas sejam gerenciadas em conformidade com o processo decisório apresentado na figura 1 a seguir (GOLDRATT, 2014): 


\section{conghESSO CIENCIAESOCIEDADE \\ Inovação, Diversidadie e Sustentahilitiladile}

Figura 1 - Etapas da Teoria das Restrições

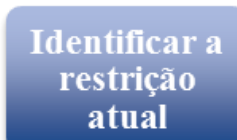

Identificar a atual
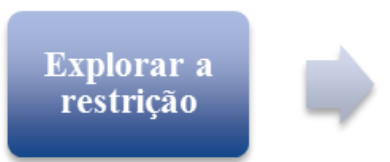

Repetir as

etapas

Fonte: Autoria própria (2019)

\section{Revisar \\ todas as \\ outras \\ atividades}

Elevar a

restrição

\section{IDENTIFICAÇÃO DO FLUXO DE MERCADORIAS - ATUAL}

O processo de recebimento de produtos do segmento de móveis e eletrodomésticos segue passos similares, porém, o tempo estipulado para tal processo varia conforme tipo de mercadoria e quantidade de volumes. O tempo inicia-se com a entrada do caminhão no CD e finaliza com a conferência cega dos produtos contidos na nota fiscal do fornecedor.

O fluxo do processo de recebimento pode ser definido pelos seguintes passos: (1) Recebimento de notas fiscais, credenciamento da equipe de descarga, definição de ordem de descarga; (2) Entrada no CD; (3) Descarga de produtos na plataforma de recebimento, confirmação de códigos e quantidades; (4) Conferência de nota fiscal no sistema, liberação para finalização de recebimento. A figura 2 apresentada a seguir ilustra o fluxo descrito:

Figura 2 - Etapas do Processo de Recebimento

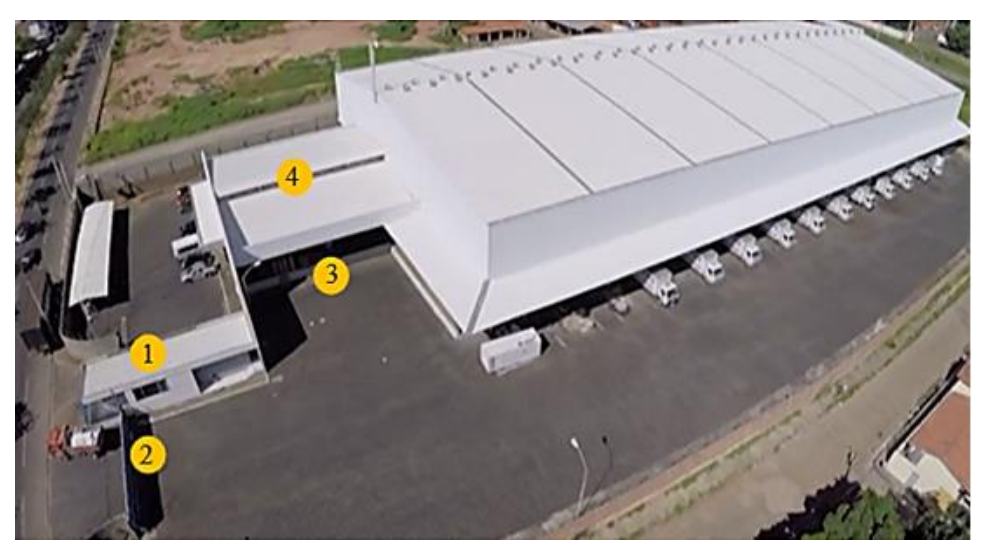

Fonte: Autoria própria (2019) 


\section{conghESSOCIENCIAESOCIEDADE \\ -}

O centro de distribuição em estudo possui 4 docas para recebimento de mercadorias e a capacidade de cada doca varia conforme o tipo de produto que será recebido. A empresa trabalha com dois turnos, totalizando 8 horas por dia.

Para que se possa compreender melhor, na figura 3 tem-se o desenho do fluxo apresentado por meio de fluxograma.

Figura 3 - Fluxograma do Recebimento

\section{Recebimento \\ de notas \\ fiscais}

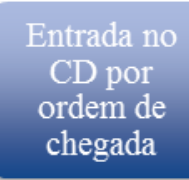

Descarga de

mercadorias
Conferência

da nota fiscal

e liberação.

Fonte: Autoria própria (2019)

É importante ressaltar que o tempo de espera na fila não é contabilizado como tempo de descarga. A tabela 1 a seguir indica o tempo médio de descarregamento nas docas e a quantidade mínima de ajudantes solicitados pela empresa para seus fornecedores/transportadores.

Tabela 1 - Normatização para Recebimento

\begin{tabular}{c|c|c|c}
\hline MERCADORIA & \multicolumn{2}{|c|}{ QUANTIDADE MíNIMA DE AJUDANTES } & TEMPO P/DESCARREGAR \\
\hline Colchão & 2 ajudantes até 250 volumes & 3 ajudantes a partir de 251 volumes & 1 hora (em média) a cada 90 volumes \\
\hline Madeira & 3 ajudantes a partir de 300 volumes & 4 ajudantes a partir de 301 volumes & 1 hora (em média) a cada 160 volumes \\
\hline Estofado & 2 ajudantes até 80 volumes & 3 ajudantes a partir de 81 volumes & 1 hora (em média) a cada 80 volumes \\
\hline Eletro & 2 ajudantes até 400 volumes & 3 ajudantes a partir de 401 volumes & 1:30 hora (em média) a cada 100 volumes \\
\hline Linha Branca & \multicolumn{2}{|c|}{ 3 ajudantes } & 1 hora (em média) a cada 200 volumes \\
\hline Tapetes & 2 ajudantes & 1 hora (em média) a cada 250 volumes \\
\hline
\end{tabular}

Fonte: Autoria própria (2019)

O estudo do tempo de execução realizado para a determinação do tempo padrão considerou o efetivo e equipamentos disponíveis pela empresa. A tabela 2 retrata tais componentes do processo em análise: 


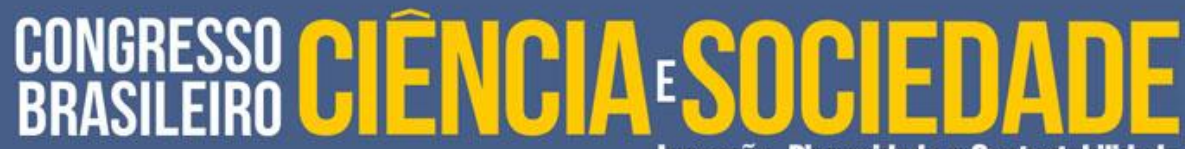 \\ Inovação, Diversidladie e Sustentalililitaile}

Tabela 2 - Componentes do Recebimento

\begin{tabular}{c|c|c}
\hline SETOR & \multicolumn{2}{|c}{ RECURSO } \\
\hline Recepção & 1 operador & - \\
\hline Conferência & 2 operadores & \multirow{2}{*}{ 1 transpaleteira; 2 paleteiras } \\
\hline Armazenagem & 1 operador & \\
\hline Liberação Nota Fiscal & 1 operador & - \\
\hline
\end{tabular}

Fonte: Autoria própria (2019)

Nessa etapa, foi possível identificar alguns pontos: equipamentos danificados (paleteiras manuais), equipe de recebimento reduzida, que resulta em atraso do fluxo recebimento $x$ armazenamento e indisponibilidade de espaço para recebimento de novos produtos. Tais pontos são classificados como limitadores.

Os custos com pessoal para descarga de mercadorias são por conta da fábrica/fornecedor. No momento do envio do pedido de compra, encaminha-se a normatização do CD, contendo a quantidade de colaboradores necessários relativos a quantidade de volumes da carga, além disso, tem-se o tempo médio para descarga desses volumes. A tabela 3 a seguir refere-se aos dois meses do primeiro semestre de 2019, mostrando os tempos gerados com a descarga de mercadorias nesse período.

Tabela 3 - Tempo gerado com atrasos

\begin{tabular}{c|c|c|c}
\hline Mês & Total de caminhões & Qtde com tempo excedente & Horas (a mais) \\
\hline Fevereiro & 35 & 12 & $15 \mathrm{~h} 50 \mathrm{~min}$ \\
\hline Março & 32 & 11 & $17 \mathrm{~h} 15 \mathrm{~min}$ \\
\hline
\end{tabular}

Fonte: Autoria própria (2019)

Com os dados da tabela 3, é possível perceber que, mais de $34 \%$ dos caminhões que abastecem o Centro de Distribuição, ultrapassam o tempo acordado para descarga de mercadorias. O tempo excedido gera gasto na medida em que impede a entrada de outro veículo. Este custo não é contabilizado pela empresa.

\section{ANÁLISE E DISCUSSÃO DOS RESULTADOS: APLICAÇÃO DA TEORIA DAS RESTRIÇÕES}




\section{CONGQBESSOCIENCIAESOCIEDADE \\ Inovação, Diversidaale e Sustentahilitilade}

Neste tópico serão apresentadas as análises e inferências acerca da aplicação da teoria das restrições no $C D$ da empresa que foi objeto de estudo de caso. As análises foram feitas após imersão no ambiente investigado, coletando-se documentos e relatórios por meio de pesquisa documental, além das observações realizadas diretamente sobre o CD e os processos presenciados.

\section{Mapeamento da Capacidade - Recebimento}

Aqui é apresentada a descrição e análise do mapeamento da capacidade em relação ao recebimento no CD. Com tal explanação, a ineficiência no cumprimento dos prazos de descarga propõe uma falha no processo de recebimento em estudo. Diante do exposto, a capacidade real do CD pode ser entendida por meio da tabela 4 a seguir:

Tabela 4 - Capacidade Real

\begin{tabular}{c|c|c}
\hline RECURSOS & \multicolumn{2}{c}{ CAPACIDADE } \\
\hline Pátio & 458,01 & $\mathrm{~m}^{2}$ \\
\hline Mão de Obra & 5 & Equipe \\
\hline \multirow{3}{*}{ Máquinas } & Transpaleteira: 1 & \multirow{2}{*}{ Unid. } \\
\cline { 2 - 2 } & Empilhadeira: 1 & \multirow{2}{*}{} \\
\cline { 2 - 2 } & Paleteira: 4 & \\
\hline Tempo & 61 & horas/semana \\
\hline Doca & 4 & Espaços \\
\hline
\end{tabular}

Fonte: Autoria própria (2019)

A partir do levantamento da capacidade da área de recebimento da empresa, foi possível avaliar a quantidade de volumes máxima para cada linha de produto do Centro de Distribuição. Com isso, o agendamento de caminhões, que é feito antecipadamente, limita a quantidade de volumes diários a serem recebidos. Na tabela 5 é possível visualizar a capacidade de recebimento de cada linha de produto: 


\section{CONGEESSO CIENCIAESOCIEDADE -}

Tabela 5 - Capacidade por Linha de Produto

\begin{tabular}{c|c|c|c}
\hline PRODUTO & CAPACIDADE (vol/dia) & CAPACIDADE (espaço) & Capacidade Limitante \\
\hline Colchão & 990 & 805 & 805 \\
\hline Madeira & 1.760 & 4562 & 1.760 \\
\hline Estofado & 880 & 447 & 447 \\
\hline Eletro & 733 & 27.480 & 733 \\
\hline Linha Branca & 2.200 & 948 & 948 \\
\hline
\end{tabular}

Fonte: Autoria própria (2019)

A área de recebimento é suficiente para receber a quantidade de caminhões que são agendados diariamente. Durante a análise do tempo de atraso de recebimento das mercadorias, fez-se um levantamento dos principais pontos observados que possivelmente justificam tal atraso. Dos 23 caminhões que geraram atraso no fluxo de recebimento, apresentados na tabela 3, constatou-se que em 10 deles, tratava-se de recebimento de linha Madeira.

Ao observar o recebimento desta linha de produtos, pode-se concluir que dos recebimentos que atrasaram, o máximo de volumes recebidos foi de 1342. Este dado leva a constatação de que a capacidade limitante é suficiente para a máxima quantidade recebida. Constatou-se também uma peculiaridade que o difere dos demais. Os itens de Madeira tais como: roupeiros, racks, estantes, etc. são compostos por vários volumes para sua formação final de venda. Cada peça de um roupeiro, por exemplo, é tido como um volume do produto. Assim sendo, quando somado os itens (espelho, portas, gavetas, fundo, piso, etc.) tem-se o produto "Roupeiro" completo. Na carga destes produtos, os volumes vêm separados e descarregados um a um aleatoriamente e, além disso, a empresa opta por armazenar os volumes de um mesmo produto juntos. Isso requer um desprendimento maior por parte dos colaboradores internos, por se tratar de itens pesados e com grande número de volumes.

Como a mão de obra disponível para a área de recebimento é limitada (somente 2 colaboradores internos), o processo fica moroso, pois mesmo a quantidade de ajudantes sendo a requisitada na normatização da empresa no ato do agendamento de entrega, estes não possuem entendimento do processo e oferecem somente a força física para o descarregamento de materiais, ficando para os colaboradores da empresa a organização dos volumes nos pallets bem como a conferência de todos os volumes e quantidades de cada produto. 


\section{COMGEFSSOCOENCIA BSA \\ -}

Observou-se também que, em 4 dos casos de atraso, tratava-se da quantidade de ajudantes nos caminhões inferiores ao requisitado em normatização pela empresa. É importante que seja cobrada atenção quanto à quantidade mínima de ajudantes visto que a empresa dispõe de colaboradores somente para conferencia e organização dos produtos em descarga. Além disso, o tempo padrão adotado para as linhas de produtos levam em consideração a quantidade mínima exigida para que se alcance o tempo médio determinado. Se não cumprido, pode acarretar atrasos nos demais recebimentos agendados para o dia.

Por fim, 7 dos atrasos se deram em cargas de eletrodomésticos da linha branca tais como: refrigeradores, freezers, fogões, lavadoras, etc. Durante a observação, constatou-se que as dimensões de tais produtos retardam o fluxo de recebimento no que se refere ao manuseio dos mesmos. Sugere-se que a empresa reveja o tempo padrão adotado para a descarga desses itens, entendendo a fragilidade e dificuldade de manuseio e alocação dos mesmos nos pallets.

É importante ressaltar que nos meses em estudo, o Centro de Distribuição estava operando com apenas $36 \%$ da sua capacidade de recebimento, por se tratar de meses em que a empresa inicia os pedidos para o período de alta nas vendas. Tendo em vista tais atrasos mesmo em baixa operação, é preciso que se tenha um plano de contingência para períodos de alta ocupação, com recursos humanos e equipamentos necessários para que o fluxo não seja interrompido.

\section{Mapa da Capacidade - Pessoal}

As observações análises também permitiram o mapeamento da capacidade relacionada ao pessoal, o que indicou que a mão de obra é o gargalo do sistema, pois a causa de atrasos se dá tanto com relação à quantidade de colaboradores internos quanto aos externos, pois a quantidade que é necessária para a continuidade do fluxo é insuficiente. A figura 4 mostra o dimensionamento da capacidade real do pessoal responsável pelo recebimento de produtos da empresa. 


\section{CONGEESSO CIENCIAESOCIEDADE -}

Figura 4 - Capacidade do Pessoal
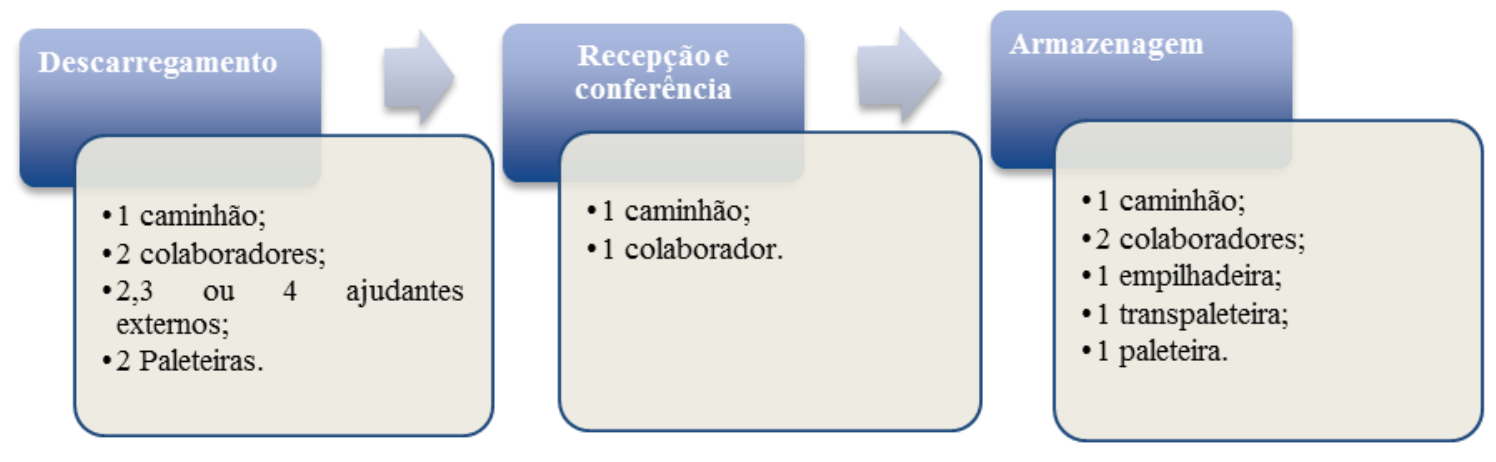

Fonte: Autoria própria (2019)

Todos os produtos englobam as etapas de recepção, descarga e conferência. As docas de recebimento da empresa suportam, no máximo, quatro caminhões simultaneamente, no entanto o número de colaboradores atual limita o recebimento para apenas 1 caminhão. Uma possível solução seria o remanejamento de colaboradores dos setores adjuntos para o descarregamento, otimizando os processos e aumentando o número de veículos nas docas.

No espaço de recepção, os produtos ocupam o espaço disponível até que os colaboradores internos finalizem o processo de etiquetagem na descarga e destinem as mercadorias para os espaços de estoque. Como os recebimentos são agendados, há uma preocupação em intercalar produtos que ocupam muito espaço da área de recepção e os que não ocupam tanto. De acordo com a análise, o espaço da recepção não tem impacto no atraso da descarga de caminhões. Além disso, as docas não são todas utilizadas, no caso de períodos com maior número de mercadorias para receber, as docas poderiam servir como pulmão para os produtos recebidos.

\section{CONCLUSÃO}

O estudo desenvolvido alcançou seu objetivo geral na medida em que identificou o gargalo presente no fluxo de recebimento do centro de distribuição, bem como foram realizadas diversas análises que permitiram o desenvolvimento de estratégias para fazer frente à situação exposta, bem como realizar melhorias.

As análises do fluxo do processo de recebimento mostraram as falhas na etapa de descarga de mercadorias, onde esse processo ultrapassa o tempo estipulado na normatização adotado pela empresa, o que leva ao não atingimento das metas setoriais estabelecidas. 
A mão de obra surge como o gargalo do sistema de recebimento, pois não são suficientes para a capacidade das docas. Foram feitas sugestões de melhorias ao longo da discussão, indicando que a etapa de descarga é a mais ineficiente. Os demais recursos estão adequados à demanda atual, porém, para os períodos com maior utilização da capacidade, será necessário revê-los.

Somado às sugestões citadas é preciso que sejam reavaliados todos os recursos envolvidos no processo de recebimento, além do recálculo do tempo médio para descarga contido na normatização da empresa. Tais atitudes permitem a melhoria do fluxo de recebimento recaindo no serviço prestado pela empresa e diminuição dos tempos de paradas desperdiçados com gargalos do fluxo.

Sugere-se que seja feito um estudo mais detalhado em relação ao fluxo ampliado, ou seja, não apenas do processo de recebimento, mas considerando toda a cadeia de valor desde o fornecedor até o cliente final. Isso pode clarificar os impactos decorrentes da restrição descoberta no processo de recebimento.

\section{REFERÊNCIAS}

BARBROW, S.; HARTLINE, M. Process mapping as organizational assessment in academic Librarie. Performance Measurement and Metrics, v. 16, n. 1, p. 34-47, 2015.

GIL, A.C. Métodos e técnicas de pesquisa social. 6. Ed. São Paulo: Atlas, 2009.

GOLDRATT, E. M.; COX, J. A meta: um processo aprimorado contínuo. 2. ed. São Paulo: Nobel, 2014.

MARETH, T.; ALVES, T. W.; BORBA, G. S. Mapeamento de processos e simulação como procedimentos de apoio à gestão de custos: uma aplicação para o processo de registros e matrículas da universidade de cruz alta. In: IX CONGRESSO USP, 2003. Anais... São Paulo, 2009.

MELO, Daniela de Castro; ALCÂNTARA, Rosane Lúcia Chicarelli. A gestão da demanda em cadeias de suprimentos: uma abordagem além da previsão de vendas. Gestão \& Produção, v. 18, n. 4, p. 809-824, 2011.

MILAN, G. S.; VERSETTI, R. Melhorias em processos com impacto na eficiência operacional: um estudo ambientado em um laboratório de análises clínicas. Revista Produção Online, Florianópolis - SC, v.12, n. 4, p. 1031-1056, 2012.

ROESCH, Sylvia Maria Azevedo. Projetos de estágio e de pesquisa em administração: guia para estágios, trabalhos de conclusão, dissertações e estudos de caso. 3. ed. São Paulo: Atlass, 2013. 


\section{CONGEESSO CIENCIAESOCIEDADE \\ Inovação, Diversillatie e Sustentahililitadie}

SLACK, N.; CHAMBERS, S.; JOHNSTON, R. Administração da Produção. 8a Ed. São Paulo: Atlas, 2018. 